\title{
Adult Glass Ingestion: A Case Report and Review of Literature
}

\author{
Blaire Anderson ${ }^{\mathrm{a}, \mathrm{c}}$, Shahzeer Karmali ${ }^{\mathrm{a}, \mathrm{b}}$
}

\begin{abstract}
While foreign body ingestion occurs most often in children, adult ingestion has been reported. Most cases can be managed with close observation. Endoscopic and surgical retrieval are options when other management fails or complications arise. We present a case of a 31-year-old male who presented to the emergency department with hematemesis and abdominal pain. The patient had deliberately ingested broken glass. Psychiatric crisis precipitated the event and for this patient it was found to be a repetitive occurrence. This case report emphasizes the different management options and the importance of a multidisciplinary approach in patients with underlying psychiatric pathology.
\end{abstract}

Keywords: Foreign body; Glass ingestion; Adult

\section{Introduction}

Foreign body ingestion occurs with much greater frequency in children with peak incidence between 6 months to 6 years [1]. Adult foreign body ingestion usually occurs accidently, for example bones with food; however deliberate ingestion accounts for $10 \%$ of cases in adults [2]. This pattern is usually repetitive and occurs in patients with intellectual disability, substance abuse, psychiatric disorders, and external motivators (avoidance of jail) [3]. Management of these patients proves to be particularly challenging, therefore a

\footnotetext{
Manuscript accepted for publication May 16, 2013

${ }^{a}$ Department of Surgery, University of Alberta, 8440 - 112 St, Edmonton, Alberta, T6G 2B7, Canada

${ }^{\mathrm{b}}$ Center for the Advancement of Minimally Invasive Surgery (CAMIS), Royal Alexandra Hospital, Room 405 Community Services Center, 10240 Kingsway, Edmonton, Alberta, T5H 3V9, Canada

${ }^{\mathrm{c} C}$ Corresponding author: Blaire Anderson, Department of Surgery, University of Alberta, 8440 - 112 St, Edmonton, Alberta, T6G 2B7,

Canada. Email: blanders@ualberta.ca
}

doi: http://dx.doi.org/10.4021/jmc1284w multidisciplinary approach including medical, surgical, and psychiatric interventions is crucial. These patients consume innumerable hospital resources and care can be very costly. In some instances, where underlying psychiatric pathology is identified, certain types of care can be counterproductive.

The majority of the time, $80-90 \%$, the object passes without intervention, $10-20 \%$ of the time endoscopic retrieval is necessary, and in $<1 \%$ of cases surgical removal is required [4-9]. Conservative management with close observation is warranted in most cases. Endoscopic removal is efficacious and safe, and is required in situations where conservative management is risky or fails [10]. Risk can be estimated based on the specific situation including type, shape, and location of foreign body, symptomatology, time since ingestion, and evidence of complications including perforation or bleeding [11].

Magnets and batteries provide special challenges. When more than one magnet is ingested they have a tendency to attract each other through the gastrointestinal wall leading to serious complications including bowel necrosis, perforation, obstruction, fistula formation, volvulus, and even death [12]. With battery ingestion comes concerns regarding erosion, perforation, and death. Risks include generation of electrical current, leakage of battery contents, local pressure, and heavy metal toxicity [13].

Absolute indication for surgical intervention is perforation of the gastrointestinal tract. Relative indication includes complications not amendable to endoscopic intervention including objects that are stuck. Anatomical abnormalities including Schatzki ring, hiatal hernia, or in our case restrictive ostomy provide particular challenges [14].

\section{Case Report}

A 31-year-old male presented to the emergency department with a history of hematemesis and diffuse abdominal pain. He reported no relief of this pain with his usual narcotic medications and had been experiencing nausea with an inability to tolerate food or fluids. Vital signs were within normal limits. Complete physical exam revealed a diffusely tender abdomen with no signs of peritonitis. Imaging stud- 

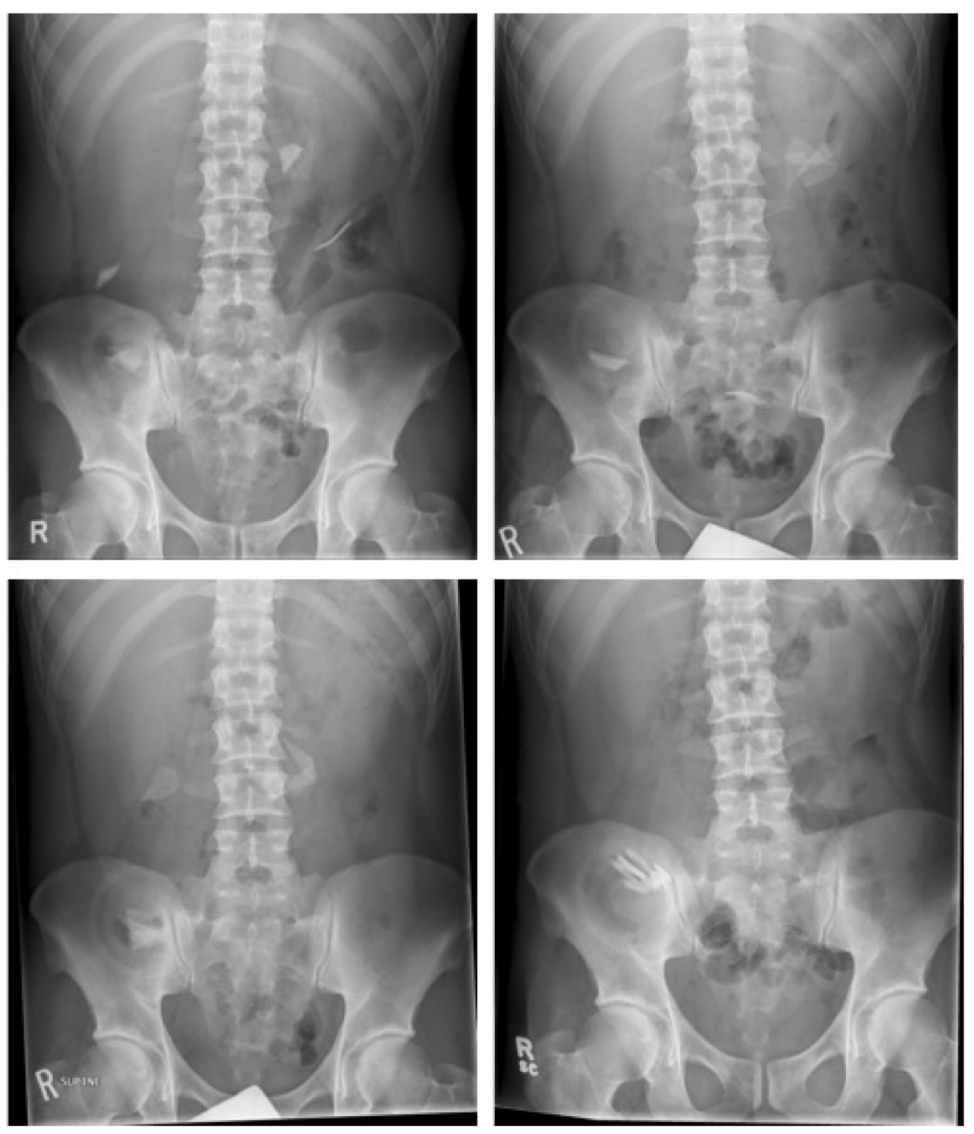

Figure 1. Serial images showing progression of swallowed glass to ileostomy site.

ies showed no evidence of pneumoperitoneum or pneumomediastinum; however several foreign bodies were visible throughout the gastrointestinal tract (Fig. 1, 2).

On further history it was elucidated that life circumstances precipitated a psychiatric crisis, which led to the patient ingesting a broken glass. Review of the patient's medical chart revealed multiple foreign body ingestions. The patient had visited the emergency department 115 times in the past

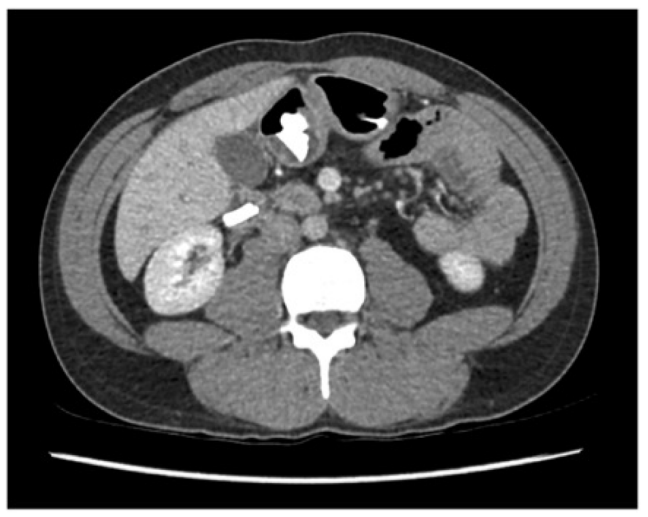

Figure 2. CT scan showing several glass shards in the stomach and duodenum with no evidence of free fluid or free air. year with complaints of abdominal pain and had ingested foreign bodies fifteen times in the three weeks preceding the current presentation. On several occasions he was managed with close observation; however he required nine therapeutic endoscopies for definitive management after failure to pass the offending objects or further ingestion of foreign bodies while hospitalized.

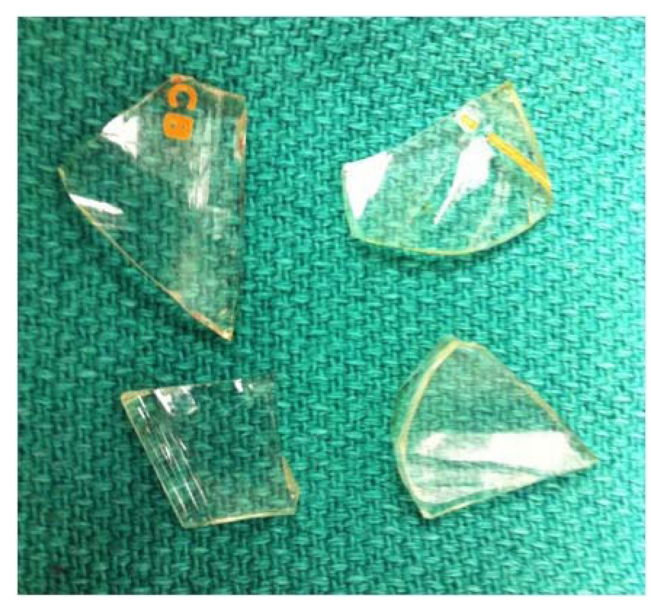

Figure 3. Glass shards removed via enterotomy. 
The patient's past medical history was significant for inflammatory bowel disease, chronic abdominal pain, narcotic abuse, depression, previous suicidal ideation, and multiple foreign body ingestions. He was initially thought to have ulcerative colitis and underwent a total colectomy with ileoanal pouch. Subsequently he developed pouchitis and a diagnosis of Crohn's was made. His pouch was resected and ultimately permanent proctectomy with ileostomy was performed.

On this occasion, the patient was admitted to the GI service for observation. After partially successful endoscopic intervention with failure to pass the remaining glass from his ileostomy, general surgery was consulted and the patient was taken to the operating theatre. Ileoscopy was attempted, and two pieces of glass were identified; however removal was not possible. Therefore laparotomy with adhesiolysis and enterotomy for removal of foreign bodies occurred (Fig. 3).

The psychiatry liaison service was involved in the care of our patient, as ingestions seemed to be triggered by psychiatric issues. Interestingly, length of patient stay was most affected by this patient's psychiatric health, rather than delay in endoscopic management or complications related to ingestion. There is some debate as to whether hospitalization may be counterproductive in some instances by reinforcing behaviors. Perhaps outpatient management may be more appropriate if medical and psychiatric states allows.

\section{Discussion}

Most cases of foreign body ingestion can be managed with watchful waiting and close observation. Endoscopic removal is a safe and efficacious option when conservative management is deemed to be too risky, or fails. Surgical intervention is not often required; however provides definitive management in select cases. A multidisciplinary approach is crucial when dealing with repetitive deliberate ingestors, as underlying psychiatric diagnosis is often present.

\section{Competing Interests}

The authors declare no competing interests.

\section{References}

1. Cheng W, Tam PK. Foreign-body ingestion in children: experience with 1,265 cases. J Pediatr Surg.
1999;34(10):1472-1476

2. O'Sullivan ST, Reardon CM, McGreal GT, Hehir DJ, Kirwan WO, Brady MP. Deliberate ingestion of foreign bodies by institutionalised psychiatric hospital patients and prison inmates. Ir J Med Sci. 1996;165(4):294296.

3. Palese C, Al-Kawas FH. Repeat intentional foreign body ingestion: the importance of a multidisciplinary approach. Gastroenterol Hepatol (N Y). 2012;8(7):485486.

4. Webb WA. Management of foreign bodies of the upper gastrointestinal tract: update. Gastrointest Endosc. 1995;41(1):39-51.

5. Sung SH, Jeon SW, Son HS, Kim SK, Jung MK, Cho $\mathrm{CM}$, Tak WY, et al. Factors predictive of risk for complications in patients with oesophageal foreign bodies. Dig Liver Dis. 2011;43(8):632-635.

6. Chiu YH, Hou SK, Chen SC, How CK, Lam C, Kao WF, Yen DH, et al. Diagnosis and endoscopic management of upper gastrointestinal foreign bodies. Am J Med Sci. 2012;343(3):192-195.

7. Ginsberg GG. Management of ingested foreign objects and food bolus impactions. Gastrointest Endosc. 1995;41(1):33-38.

8. Peng A, Li Y, Xiao Z, Wu W. Study of clinical treatment of esophageal foreign body-induced esophageal perforation with lethal complications. Eur Arch Otorhinolaryngol. 2012;269(9):2027-2036.

9. Ikenberry SO, Jue TL, Anderson MA, Appalaneni V, Banerjee S, Ben-Menachem T, Decker GA, et al. Management of ingested foreign bodies and food impactions. Gastrointest Endosc. 2011;73(6):1085-1091.

10. Katsinelos P, Kountouras J, Paroutoglou G, Zavos C, Mimidis K, Chatzimavroudis G. Endoscopic techniques and management of foreign body ingestion and food bolus impaction in the upper gastrointestinal tract: a retrospective analysis of 139 cases. J Clin Gastroenterol. 2006;40(9):784-789.

11. Smith MT, Wong RK. Foreign bodies. Gastrointest Endosc Clin N Am. 2007;17(2):361-382, vii.

12. Liu S, Li J, Lv Y. Gastrointestinal damage caused by swallowing multiple magnets. Front Med. 2012;6(3):280287.

13. Litovitz T, Whitaker N, Clark L, White NC, Marsolek M. Emerging battery-ingestion hazard: clinical implications. Pediatrics. 2010;125(6):1168-1177.

14. Ambe P, Weber SA, Schauer M, Knoefel WT. Swallowed foreign bodies in adults. Dtsch Arztebl Int. 2012;109(50):869-875. 